\title{
Strength of the Diffusion Bonded Joints between CP Ti and 304 Stainless Steel Processed below and above $\beta$-Transus
}

\author{
M. GHOSH, K. BHANUMURTHY,1) G. B. KALE, ${ }^{1)}$ J. KRISHNAN ${ }^{2)}$ and S. CHATTERJEE
}

Department of Metallurgy, Bengal Engineering College (a Deemed University), Howrah-711103, India.

E-mail: ghosh_mnk@yahoo.com 1) Materials Science Division, Bhaba Atomic Research Centre, Mumbai-40085, India. E-mail: gbkale@apsara.barc.ernet.in $\quad$ 2) Centre of Design and Manufacture, Bhaba Atomic Research Centre, Mumbai40085, India. E-mail: gbkale@apsara.barc.ernet.in

(Received on July 23, 2003; accepted in final form on September 26, 2003)

\begin{abstract}
Diffusion bonding was carried out between commercially pure titanium and 304 stainless steel in the temperature range of $800-900^{\circ} \mathrm{C}$ for $9 \mathrm{ks}$ under uniaxial load in vacuum. The transition joints thus formed are characterized by optical metallography, scanning electron microscopy and tensile testing. The scanning images reveal the presence of different reaction bands in the diffusion zone and the composition of these bands were determined by energy dispersive spectroscopy. The concentrations of chemical species in the layers indicate the formation of intermetallics like $\sigma, \lambda, \chi$ and FeTi in the reaction zone and they were confirmed by X-ray diffraction technique. Highest bond strength (71\% of that of $\mathrm{cp} \mathrm{Ti}$ ) has been obtained for the diffusion-welded joints processed at $800^{\circ} \mathrm{C}$ owing to thinner width of brittle intermetallic phases. At high joining temperature like $900^{\circ} \mathrm{C}$, strain generation near interface along with the presence of brittle intermetallics and generation of micro-voids are responsible for lowering the bond strength of the transition joint.
\end{abstract}

KEY WORDS: diffusion bonding; intermetallic compounds; uphill diffusion; $\beta$-transus.

\section{Introduction}

Majority of the alloys used in various engineering applications involves multi-components and suitable joining techniques are required to fabricate a single component in one structure. ${ }^{1)}$ The problems become severe when, the materials to be joined, are metallurgically incompatible and vary widely in physical properties. ${ }^{2)}$ Heat affected zone (HAZ) generated by conventional fusion welding could reduce the mechanical properties and corrosion resistance of the joined component. ${ }^{3)}$ So, a significant progress has been made in the recent years to develop improved joining techniques to overcome the difficulties and in this respect diffusion bonding is an effective solution as it produces minimum macroscopic deformation and detoriation of mechanical properties of the base metals owing to low processing temperature and pressure. ${ }^{4)}$

Titanium and stainless steel are the two materials, which, can be joined by diffusion bonding, and the component finds wide applications in the processing units of Nuclear industries. ${ }^{5)}$ The success of the process depends on the characteristics of the diffusion zone formed during processing. This is a typical example of bonding two dissimilar materials with low inter-solubility and which form a number of immiscible phases in the solid state. ${ }^{6}$ Diffusion in such multi-component systems are also complex as extra degree of freedom enable interaction between solute elements leading to possibility of uphill diffusion. This occurs when the gradients of chemical potential and concentration have opposite sign. ${ }^{7)}$

The purpose of the present study is to develop transition joints with adequate strength and ductility between commercially pure titanium (cp Ti) and 304 stainless steel ( $304 \mathrm{ss}$ ) by solid-state diffusion bonding technique. Characterization of interface has been carried out to reveal the change in microstructure due to diffusion, to identify the reaction products and also to establish their influence on the properties of the joints.

\section{Experimental}

Base metals used in the present research work, were commercially pure titanium and 304 stainless steel with the dimension of $20 \mathrm{~mm}$ diameter $\times 400 \mathrm{~mm}$ length and $150 \times$ $150 \times 900 \mathrm{~mm}^{3}$ respectively. Their chemical compositions and room temperature tensile properties are given in Tables $\mathbf{1}$ and $\mathbf{2}$ respectively.

Cylindrical samples of $15 \mathrm{~mm}$ diameter and $30 \mathrm{~mm}$ length were machined from base materials. The faying surfaces were finished on $1 \mu \mathrm{m}$ diamond paste, cleaned in acetone and dried in air. The mating surfaces of the cylinders were kept in contact in an indigenously designed jig and the assembly was put in a chamber.

Diffusion bonding was carried out at 800,850 and $900^{\circ} \mathrm{C}$ for $9 \mathrm{ks}$ in the vacuum of $(4-6) \times 10^{-2} \mathrm{~Pa}$. $3 \mathrm{MPa}$ load was applied uniaxially along the longitudinal direction of the 
Table 1. Chemical compositions of the base metals

\begin{tabular}{|l|l|l|l|l|l|l|l|l|l|l|l|l|l|}
\hline Alloy & $\mathbf{C}$ & $\mathbf{F e}$ & $\mathbf{T i}$ & $\mathbf{M n}$ & $\mathbf{S i}$ & $\mathbf{P}$ & $\mathbf{S}$ & $\mathbf{C r}$ & $\mathbf{N i}$ & $\mathbf{M o}$ & $\mathbf{C u}$ & $\mathbf{O}$ & $\mathbf{N}$ \\
\hline cp Ti & 0.02 & 0.10 & $\mathrm{Bal}$ & - & - & - & - & - & - & - & - & 0.15 & 0.02 \\
\hline 304 ss & 0.01 & $\mathrm{Bal}$ & - & 1.15 & 0.23 & 0.028 & 0.012 & 21.12 & 11.45 & 0.03 & 0.08 & - & 0.11 \\
\hline
\end{tabular}

Table 2. Tensile properties of the base metals at ambient temperature.

\begin{tabular}{|c|c|c|c|}
\hline Alloy & $\mathbf{0 . 2 \%}$ proof stress(MPa) & Ultimate tensile strength(MPa) & \% Fracture elongation \\
\hline $\mathrm{cp} \mathrm{Ti}$ & 205 & 319 & 23 \\
\hline $304 \mathrm{ss}$ & 132 & 569 & 47 \\
\hline
\end{tabular}

specimens. Heating was done at the rate of $14^{\circ} \mathrm{C} \mathrm{min}^{-1}$ during processing and after joining the samples were cooled in vacuum.

From the bonded couples, a transverse section has been taken and prepared by grinding and polishing techniques. Titanium side was etched by an aqueous solution containing $\mathrm{HF}(10 \mathrm{~mL})$ and $\mathrm{HNO}_{3}(5 \mathrm{~mL})$. The etchant for $304 \mathrm{ss}$ was a mixture of $\mathrm{HNO}_{3}(10 \mathrm{~mL}), \mathrm{HCl}(30 \mathrm{~mL})$ and Glycerol $(30 \mathrm{~mL})$. The samples were observed in a light microscope (Correct SDME TR5) to reveal microstructural changes near interface. During optical microscopy, the samples were etched lightly to avoid the burning of diffusion zone and hence, all the grain boundaries of the base metals were not exposed properly. The parent materials, both as received and after diffusion bonding, were heavily etched and the grain size was measured by image analyzing software taking an average of three hundred grains. The polished samples were also examined in Scanning electron microscope (Leica S440) using back-scattered mode (SEM-BSE) to observe the different reaction layers in the diffusion zone. The composition of the reaction bands was determined by using Energy dispersive spectroscopy (Oxford 5431) and the concentration profiles of the alloying elements have been drawn. A set of bonded assemblies were fractured under shear. X-ray diffraction study has been done on the fracture surfaces of $\mathrm{cp} \mathrm{Ti}$ and $304 \mathrm{ss}$ at an operating voltage of $40 \mathrm{kV}$ and current of $20 \mathrm{~mA}$ (Philips PW 1710). Total scanning span was $20-70^{\circ}$ with a step size of $0.02^{\circ}$. Tensile testing (Instron 4204) has been done to evaluate ultimate tensile strength and breaking strain of the diffusion bonded joints at a crosshead speed of $0.05 \mathrm{~mm} \mathrm{~min}^{-1}$ using sub-size tensile specimen as per ASTM specification (Vol. 03.01 E8M-96). The interface was within the gauge length and four samples were tested at each processing parameter. The scatter in the result is incorporated in Table 4.

\section{Results and Discussion}

Optical micrographs of the diffusion-welded joints are shown in Fig. 1. The diffusion zone is free from discontinuities or cracks. Few distinct regions are observed in the microstructure. Region A denotes the presence of austenite phase of 304 ss containing annealing twins. Heavily etched band $\mathrm{B}$ is the original interface containing layers of intermetallics. $^{5)}$ Area $\mathrm{C}$ is the solid-solution zone of $\mathrm{cp} \mathrm{Ti}$ in which, $\mathrm{Fe}, \mathrm{Cr}$ and $\mathrm{Ni}$ are present. $\mathrm{Fe}$ and $\mathrm{Cr}$ are strong $\beta$ stabilizers of Ti and substantial quantity of them help to retain high temperature bcc phase of Ti even at ambient temperature; hence, this area can be designated as stabilized $\beta$ $\mathrm{Ti}^{8)}$ Zone $\mathrm{D}$ indicates the Widmanstätten $\alpha-\beta$ structure of cp Ti. Adequate amount of $\mathrm{Fe}$ and $\mathrm{Cr}$ in this zone promotes the eutectoid transformation of cp Ti and thus the dark $\alpha$-Ti phase occurs in the matrix of bright $\beta$-Ti. ${ }^{9}$

Band B of Fig. 1 has been resolved in SEM-BSE images and is given in Fig. 2 (' 0 ' point of Fig. 2 indicates ' 0 ' point of Fig. 1). Concentration profile of the alloying elements across the bond line has been drawn from EDS analysis and is shown in Fig. 3 (' 0 ' point of Fig. 3 indicates the location of ' 0 ' point of Fig. 2). A number of reaction bands are observed within the diffusion zone. Adjacent to 304 ss microstructure, a wide region has been found (Layer ii of Figs. 2(a)-2(c) and 3(a)-3(c) which comprises of mainly $\mathrm{Cr}$ (33.8-37.1 at \%) and $\mathrm{Fe}(50.2-54.4 \mathrm{at} \%)$ in association with small quantity of $\mathrm{Ti}(7.6-8.3 \mathrm{at} \%)$ and $\mathrm{Ni}(\mathrm{bal})$. This region indicates $\sigma$-phase formation. ${ }^{10)}$ Few shaded islands are also observed within the $\sigma$-phase when processed at 850 and $900^{\circ} \mathrm{C}$ joining temperatures and contain $\mathrm{Cr}$ (29.9-31.1 at $\%), \mathrm{Fe}(61.8-64.2 \mathrm{at} \%), \mathrm{Ni}(3.7-4.4 \mathrm{at} \%)$ and $\mathrm{Ti}$ (bal). These islands are also $\sigma$-phase. The difference in appearance with the earlier one occurs owing to variation in $\mathrm{Cr}, \mathrm{Fe}$ and $\mathrm{Ti}$ content. The ternary phase diagram of $\mathrm{Fe}-\mathrm{Cr}-\mathrm{Ti}$ at $800^{\circ} \mathrm{C}$ suggests that $\alpha$-Fe may contain up to $35 \mathrm{at} \% \mathrm{Cr}$ at this temperature and addition of Ti decreases the solubility of $\mathrm{Cr}^{11)}$ In the present investigation, Ti atoms migrate from cp Ti to 304 ss side and activity of $\mathrm{Cr}$ thus decreases. So, diffusion of $\mathrm{Cr}$ occurs down the activity gradient rather than down the concentration gradient. Hence, uphill diffusion of $\mathrm{Cr}$ forms a $\mathrm{Cr}$ rich region, which, in later stage transforms to $\sigma$-phase during cooling.

Close to $\sigma$-phase, a lightly shaded region has been found (Region iii of Figs. 2(a)-2(c) and 3(a)-3(c) which is enriched with $\mathrm{Ti}(25.9-42.4$ at\%), Fe (39.9-46.4 at\%) and $\mathrm{Cr}$ (12.7-23.8 at\%). It has been mentioned in literature that, in $304 \mathrm{ss}$, Ni concentration is not enough to form any Ni bearing intermetallics. ${ }^{12)}$ So, ignoring the effect of $\mathrm{Ni}$, from the isothermal section of $\mathrm{Fe}-\mathrm{Cr}$ - $\mathrm{Ti}$ diagram, it can be predicted that the region mainly contains $\lambda$-phase. ${ }^{13)} \lambda$-phase is the solid-solution of $\mathrm{Fe}_{2} \mathrm{Ti}$ and $\mathrm{Cr}_{2} \mathrm{Ti}$. With the rise in processing temperature $\mathrm{Ti}$ concentration decreases, $\mathrm{Fe}$ and $\mathrm{Cr}$ content increase in this region; hence it can be inferred that at $800^{\circ} \mathrm{C}$ with the $\lambda$-phase, FeTi may also be present and beyond $800^{\circ} \mathrm{C}, \chi$-phase may occur along with the $\lambda$-phase. ${ }^{14)}$

Next to $\lambda$-phase, a shaded zone has been observed (Zone iv of Figs. 2(a)-2(c) and 3(a)-3(c)) containing Ti (60.7$69.3 \mathrm{at} \%), \mathrm{Fe}(20.7-28.3 \mathrm{at} \%), \mathrm{Cr}(6.9-7.6 \mathrm{at} \%)$ and $\mathrm{Ni}$ (bal). The isothermal section of $\mathrm{Fe}-\mathrm{Cr}-\mathrm{Ti}$ ternary phase diagram indicates the presence of $\mathrm{FeTi}+\lambda+\beta$-Ti phase mixture in this zone. ${ }^{11)}$ Above $800^{\circ} \mathrm{C}$ bonding temperature when the width of this region enhances, the concentration of $\mathrm{Ti}$ and $\mathrm{Fe}$ vary widely across this region. At the left 

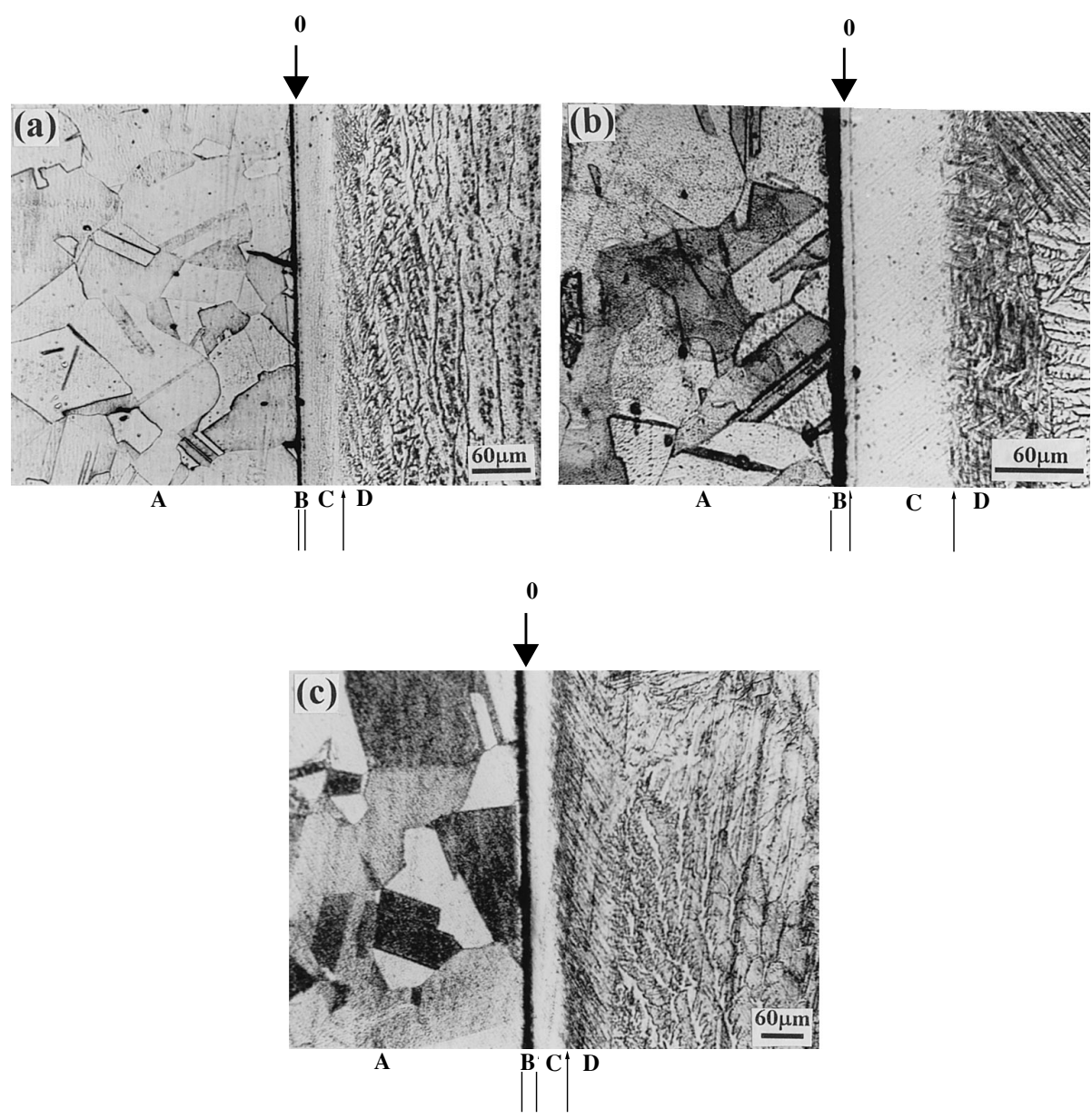

Fig. 1. Optical micrographs of the transition joints processed for $9 \mathrm{ks}$ : at (a) $800^{\circ} \mathrm{C}$, (b) $850^{\circ} \mathrm{C}$, (c) $900^{\circ} \mathrm{C}$.
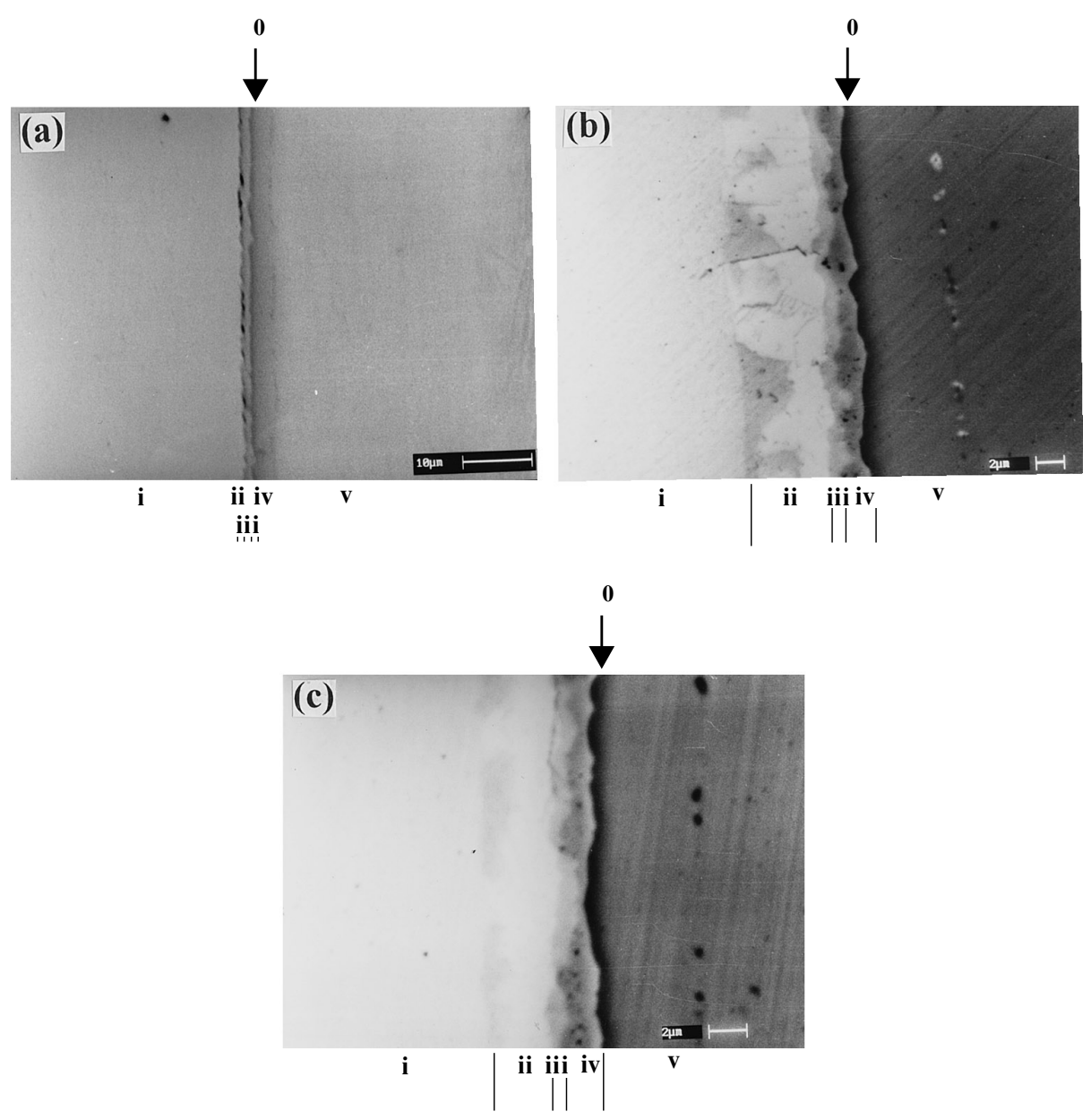

Fig. 2. SEM-BSE images of the diffusion-bonded couples processed for 9 ks: at (a) $800^{\circ} \mathrm{C}$, (b) $850^{\circ} \mathrm{C}$, (c) $900^{\circ} \mathrm{C}$. 


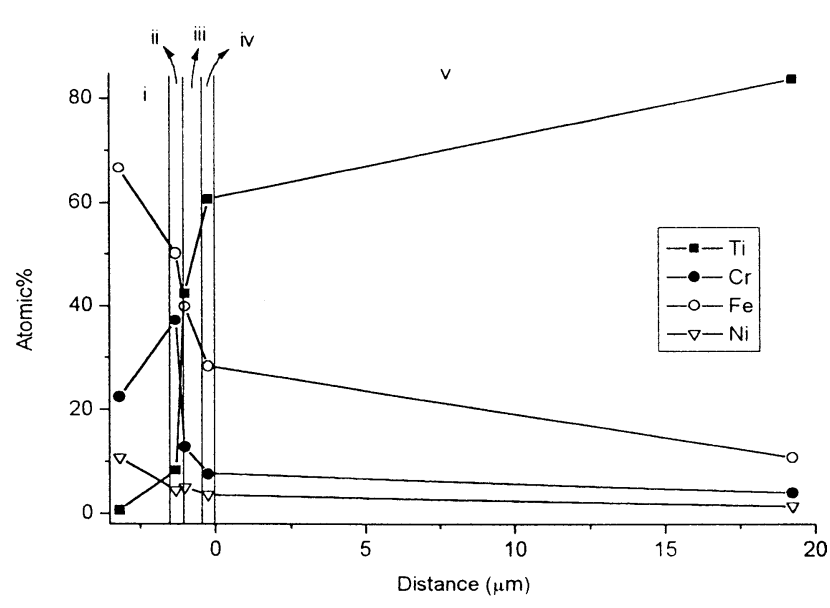

(a)

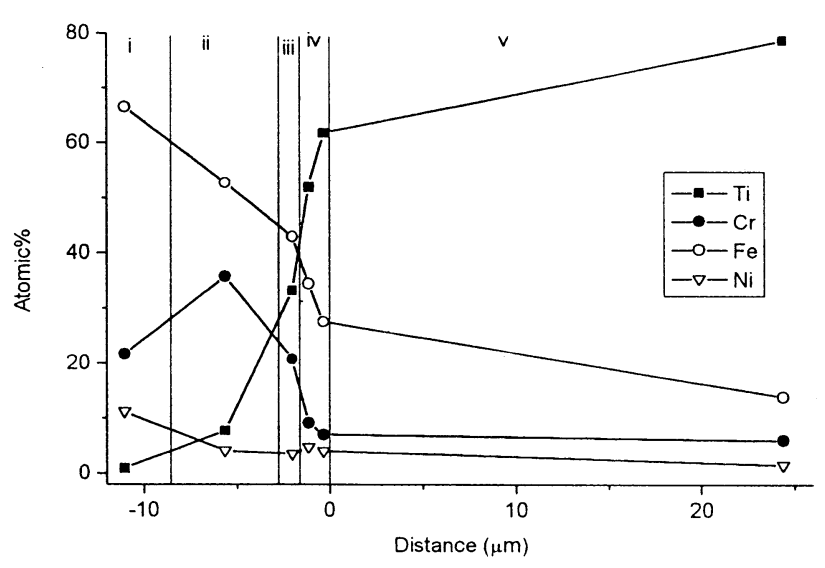

(b)

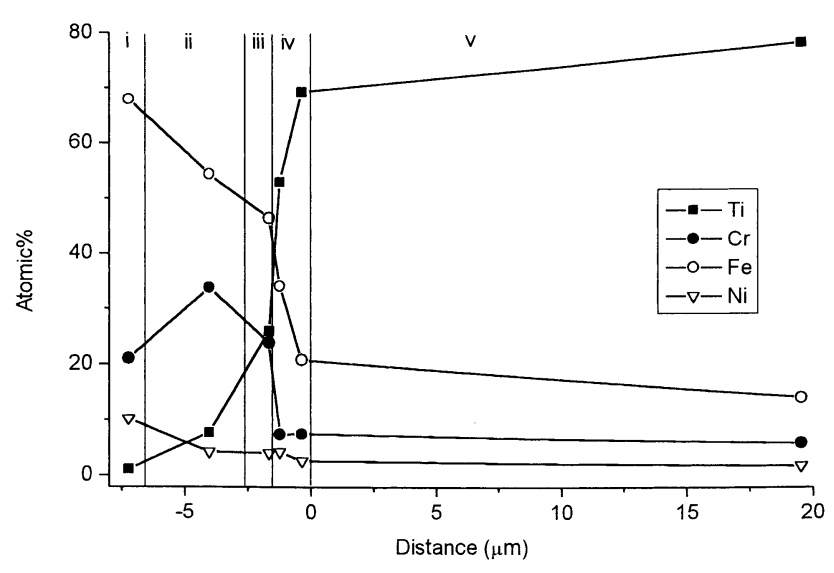

(c)

Fig. 3. Energy dispersive spectroscopy results for the specimens diffusion-bonded for $9 \mathrm{ks}$ : at (a) $800^{\circ} \mathrm{C}$, (b) $850^{\circ} \mathrm{C}$, (c) $900^{\circ} \mathrm{C}$. boundary, Ti exhibits substantial drop (51.9-53 at\%) in concentration and Fe shows enrichment (34 at \%) in comparison to the concentration mentioned earlier in the same region. Widest region of Figs. 2 and 3 (Region v) in the cp Ti side exhibits the existence of stabilized $\beta$-Ti. This region contains Ti (78.3-83.9 at\%), Fe (10.8-14.1 at\%), Cr (4-6 at $\%$ ) and $\mathrm{Ni}$ (bal).

The width of the reaction bands has been measured from the cursor position during characterization in SEM and five such readings have been taken from different locations. Average of the same is furnished in Table 3.

Literatures report that, at lower bonding temperature the growth of intermetallics is governed by the diffusion through grain boundary or by the dissociated dislocation diffusion. ${ }^{15)}$ All these structural defects are commonly known as short-circuit paths. With the increase in joining temperature, the grain boundary area decreases and bulk diffusion facilitates. Kinetic study on the layer growth shows that extent of flux transfer by bulk diffusion is less than the mass transport through short-circuit paths though the processing temperature may be higher in case of the former. ${ }^{15)}$ The same phenomenon has also been observed in the present investigation. With respect to $800^{\circ} \mathrm{C}$, the width of the reaction bands enhances at $850^{\circ} \mathrm{C}$ due to better extent of diffusion of chemical species. At $900^{\circ} \mathrm{C}, 304$ ss retains its fcc structure but $\mathrm{cp}$ Ti undergoes a phase transformation from $\alpha$ (hcp) to $\beta$ (bcc) as this temperature is above the $\beta$ transus of cp Ti. In the single-phase region grain growth of parent metals reduces the grain boundary area (Fig. 4). The grain size of the parent metals was $\sim 12 \mu \mathrm{m}$ and $\sim 14 \mu \mathrm{m}$ for $304 \mathrm{ss}$ and $\mathrm{cp}$ Ti respectively. Up to $850^{\circ} \mathrm{C}$ bonding temperature increment in grain size of stainless steel is marginal (at $800^{\circ} \mathrm{C}$, the grain size is $\sim 14 \mu \mathrm{m}$ and at $850^{\circ} \mathrm{C}$ the same is $\sim 16 \mu \mathrm{m}$ ), however, the grain growth becomes severe at $900^{\circ} \mathrm{C}$ processing temperature $(\sim 40 \mu \mathrm{m})$. The same trend is also noticed for $\mathrm{cp} \mathrm{Ti}$. At $800^{\circ} \mathrm{C}$ joining temperature the grain size is $\sim 62 \mu \mathrm{m}$, increases to a little extent $(\sim 81 \mu \mathrm{m})$ for a rise in bonding temperature to $850^{\circ} \mathrm{C}$ and the grain growth is more pronounced $(\sim 150 \mu \mathrm{m})$ at the joining temperature of $900^{\circ} \mathrm{C}$. Enhanced grain size thus leads to reduction in mass transfer and the width of intermetallic phases decreases. Again, hcp and fcc crystals are more close-packed than bcc crystals. Hence, during diffusion annealing $\mathrm{Fe}, \mathrm{Cr}$ and $\mathrm{Ni}$ traverse a longer distance in cp Ti owing to its open structure and the mean diffusion distance of these solution atoms from the interface is larger in titanium than that of $\mathrm{Ti}$ in stainless steel. ${ }^{12)}$ Therefore, it has also been noticed that with respect to $800^{\circ} \mathrm{C}$, the width of $\alpha-\beta$ region of $\mathrm{Ti}$ enhances to a smaller degree at $850^{\circ} \mathrm{C}$ bonding temperature (the values are $\sim 14 \mu \mathrm{m}$ and $\sim 35 \mu \mathrm{m}$ respectively); however, increases rapidly to $\sim 155 \mu \mathrm{m}$ for the joining temperature of $900^{\circ} \mathrm{C}$. The massive increment in the width of $\alpha-\beta$ region of titanium at $900^{\circ} \mathrm{C}$ also results in a decrement in the width of intermetallics and stabilized $\beta$

Table 3. Width of different intermetallics at various bonding temperatures.

\begin{tabular}{|c|c|c|c|c|}
\hline Processing temperature $(\mathbf{c})$ & \multicolumn{4}{|c|}{ Width of the intermetallic phases $(\boldsymbol{\mu} \mathbf{m})$} \\
\cline { 2 - 5 } & $\sigma$ & $\lambda$ & FeTi $+\lambda+\beta-\mathbf{T i}$ & Stabilized $\beta$-Ti \\
\hline 800 & 0.8 & 0.6 & 0.5 & 39.6 \\
\hline 850 & 6.0 & 1.2 & 1.8 & 68.3 \\
\hline 900 & 4.0 & 1.0 & 1.7 & 48.4 \\
\hline
\end{tabular}



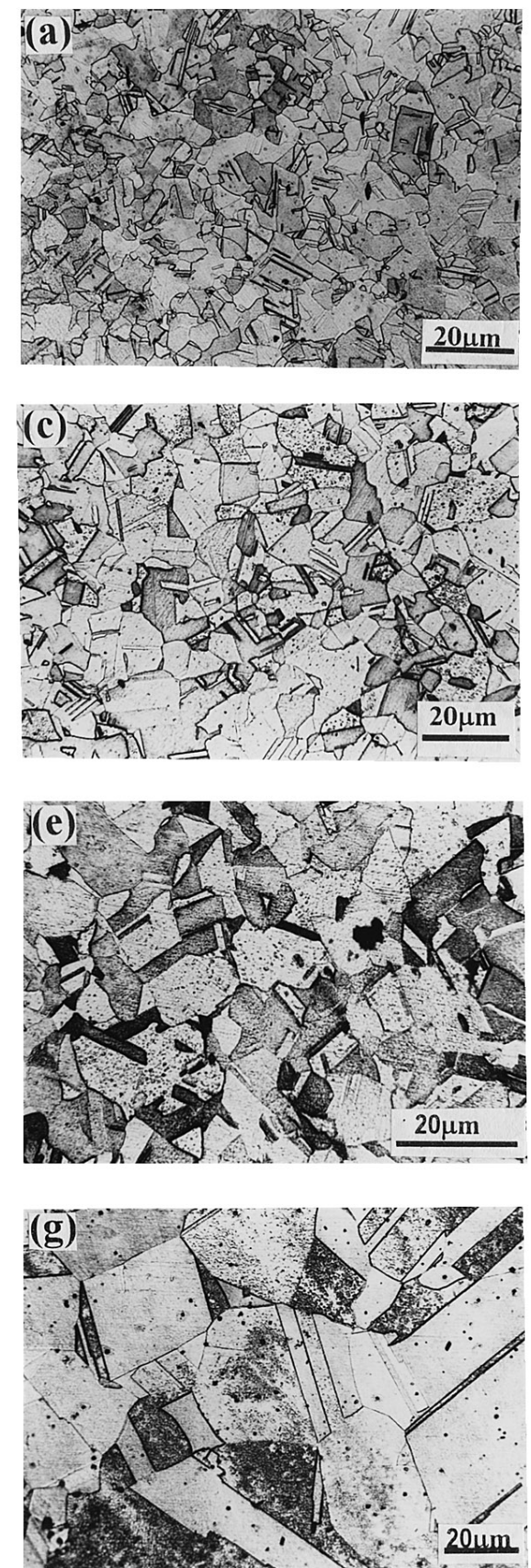
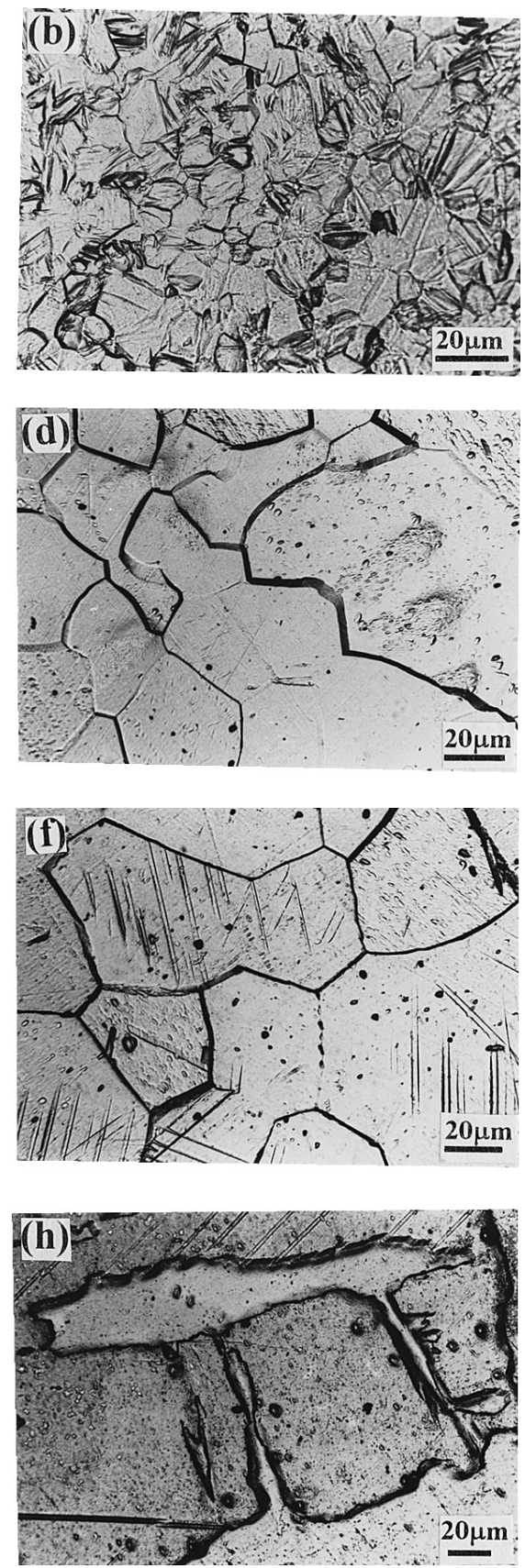

Fig. 4. Optical metallographs exhibiting the grain growth of the parent metals after diffusion annealing (a) as received $304 \mathrm{ss}$, (b) as received cp Ti, (c) $304 \mathrm{ss}, 800^{\circ} \mathrm{C}$, (d) cp Ti, $800^{\circ} \mathrm{C}$, (e) $304 \mathrm{ss}, 850^{\circ} \mathrm{C}$, (f) cp Ti, $850^{\circ} \mathrm{C}$, (g) $304 \mathrm{ss}$, $900^{\circ} \mathrm{C},(\mathrm{h}) \mathrm{cp} \mathrm{Ti}, 900^{\circ} \mathrm{C}$.

titanium.

The intermetallic compounds in the diffusion zone are identified by X-ray diffraction technique and are given in Fig. 5. It has been found that the reaction zone contains $\sigma$, $\mathrm{Fe}_{2} \mathrm{Ti}, \mathrm{Cr}_{2} \mathrm{Ti}, \mathrm{FeTi}$ and $\chi$ phases. $\mathrm{Fe}_{2} \mathrm{Ti}_{4} \mathrm{O}$ oxides, identified in XRD, have not been revealed in SEM-BSE perhaps due to their small volume fraction. The dissolved oxygen in titanium promotes the formation of the oxide. ${ }^{13)}$ The presence of $\alpha$-Fe has also been found in the reaction zone. It has been reported that during inter-diffusion in titanium-stainless steel system when the concentration of $\mathrm{Ti}$ exceeds $\sim 0.8$ at $\%$, the austenite phase transforms to bcc ferrite. ${ }^{16)}$

Tensile properties of the transition joints are furnished in Table 4. At $800^{\circ} \mathrm{C}$ bonding temperature, the brittle intermetallics like $\sigma, \lambda, \mathrm{FeTi}+\lambda$ phases exhibit minimum width; hence embrittlement becomes minimum and the UTS reaches highest level ( $71 \%$ of that of Ti) with considerable amount of ductility. It has been reported in literature that the highest bond strength of $150 \pm 20 \mathrm{MPa}$ can be obtained for the same dissimilar couple, when processing was carried out at $850^{\circ} \mathrm{C}$ for $2 \mathrm{~h}$ under $10 \mathrm{MPa}$ load. ${ }^{17)}$ In a different endeavor, maximum bond strength of $60 \%$ of that of Ti has been obtained with $\sim 2.2 \%$ ductility for the assemblies bonded within the thermal cycle of $877-927^{\circ} \mathrm{C}$ under 15.8 MPa load. ${ }^{18)}$ Hence, present investigation shows a considerable improvement in UTS and substantial increment in breaking strain. At $850^{\circ} \mathrm{C}$ bonding temperature the width of the intermetallic phase increases; hence bond strength reduces. The UTS value of the transition joints drops for further rise in joining temperature up to $900^{\circ} \mathrm{C}$ though the 
ISIJ International, Vol. 44 (2004), No. 2

(a)

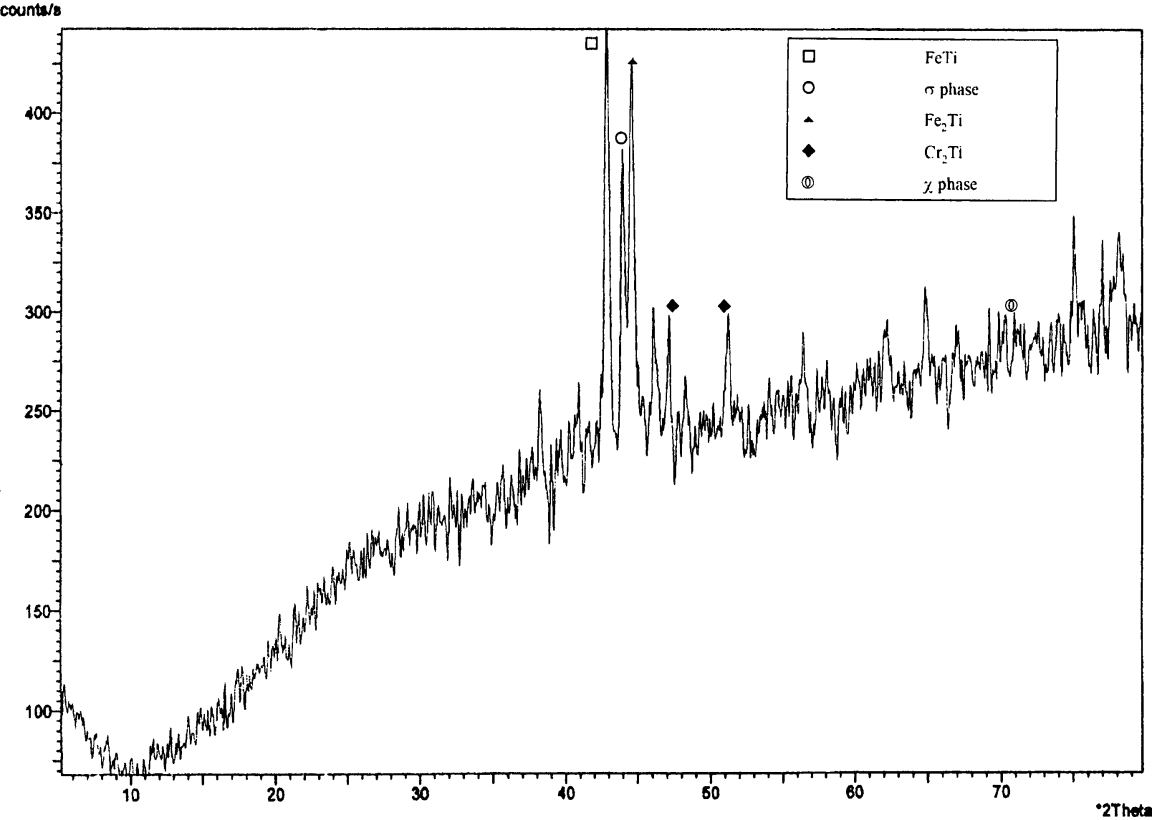

(b)

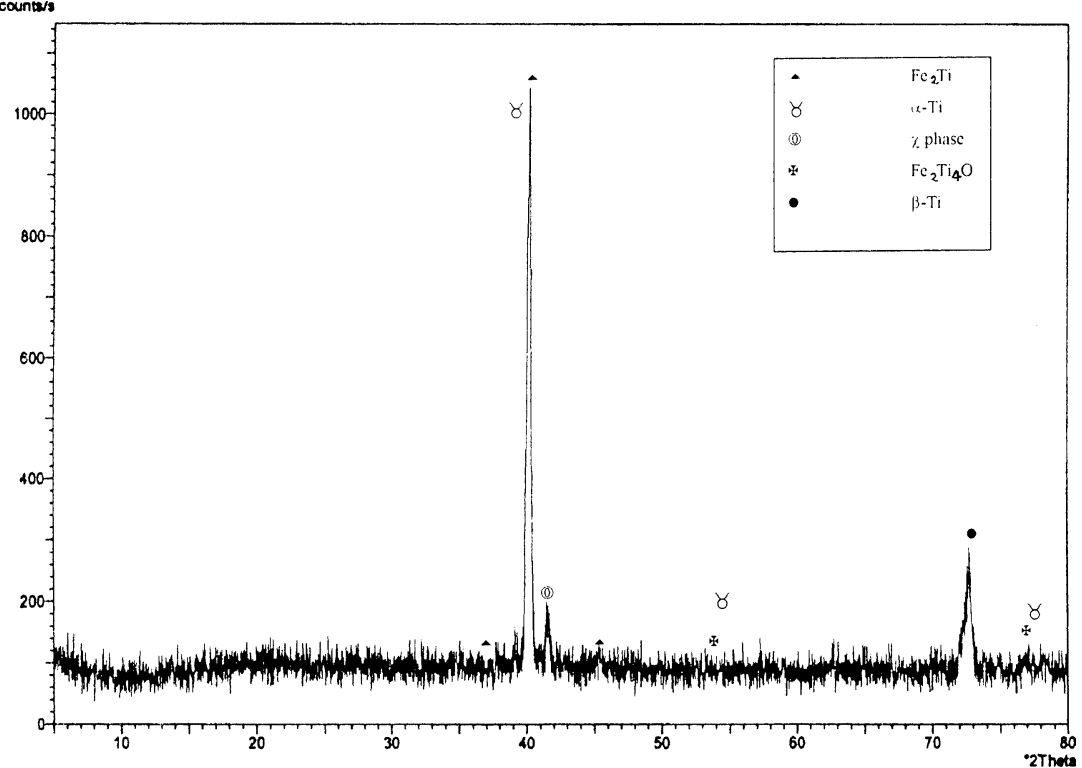

(c) [counts]

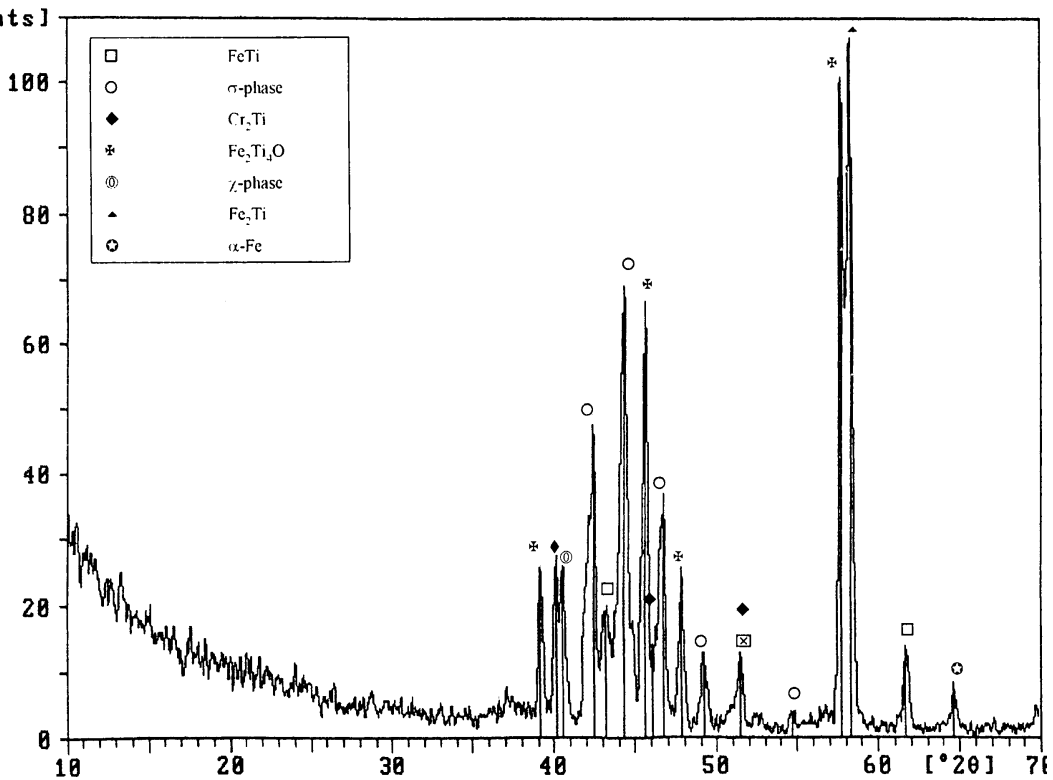

Fig. 5. 
(d)

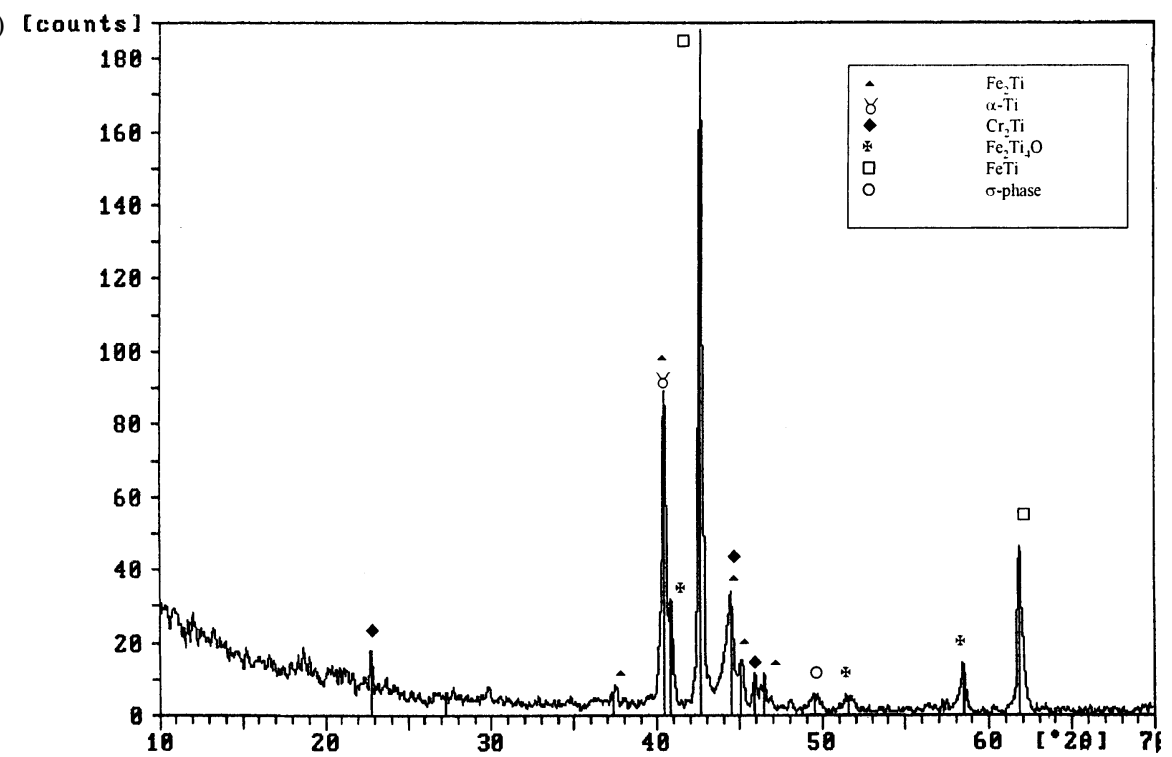

(e)

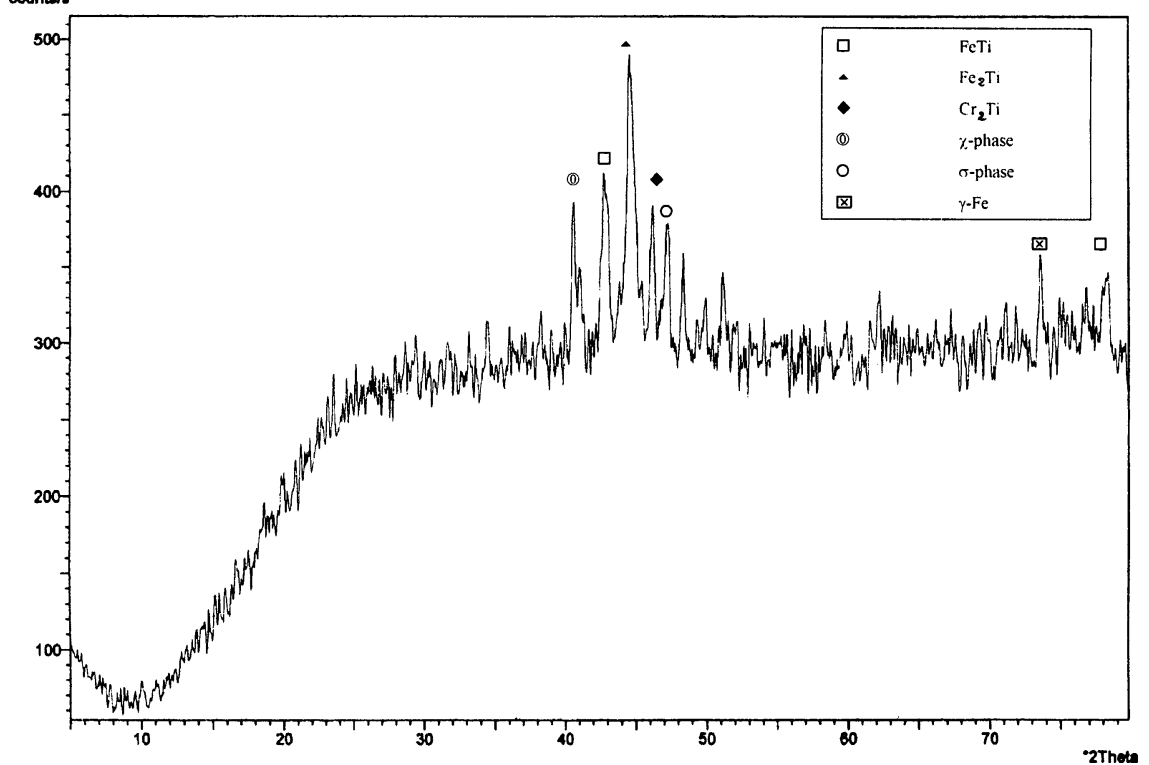

(f)

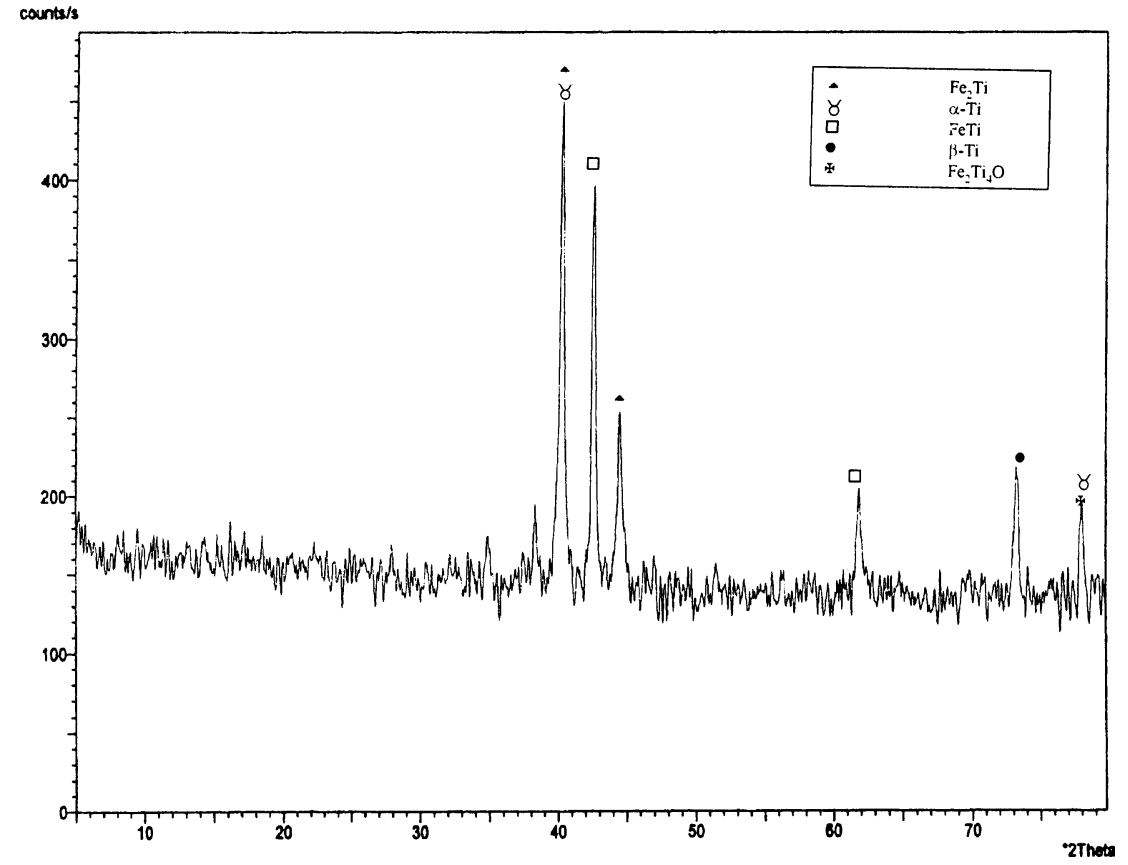

Fig. 5. X-ray diffraction pattern of fracture surfaces of the bonded couples processed for $9 \mathrm{ks}$ : (a) $800^{\circ} \mathrm{C}$, ss side, (b) $800^{\circ} \mathrm{C}$, Ti side, (c) $850^{\circ} \mathrm{C}$, ss side, (d) $850^{\circ} \mathrm{C}$, Ti side, (e) $900^{\circ} \mathrm{C}$, ss side, (f) $900^{\circ} \mathrm{C}$, Ti side. 
Table 4. Tensile properties of the bonded couples at room temperature.

\begin{tabular}{|c|c|c|}
\hline Bonding temperature $\left.\mathbf{(}^{\circ} \mathbf{C}\right)$ & Ultimate tensile strength (MPa) & Breaking strain (\%) \\
\hline 800 & $224.6 \pm 4$ & 5.7 \\
\hline 850 & $210.4 \pm 3$ & 5.3 \\
\hline 900 & $171.4 \pm 6$ & 3.2 \\
\hline
\end{tabular}

width of the intermetallic phases decreases. In the X-ray diffraction analysis, distortion and shifting of the characteristic peaks have been observed. These phenomena occur owing to strain generation near interface. Strain is generated due to difference in co-efficient of linear expansion of the parent metals and observed to be maximum at higher joining temperature. ${ }^{19)}$ The generated strain presumably plays dominant role in reducing the bond strength at $900^{\circ} \mathrm{C}$ bonding temperature; yet the effect of intermetallics cannot be ruled out. Beside the presence of intermetallics and strain generation, void formation in the reaction zone is also responsible for lowering the strength of the diffusionannealed samples. It has been illustrated earlier that, intrinsic diffusion co-efficient of titanium is higher than $\alpha$-Fe and $\gamma$-Fe (the diffusion co-efficient of Ti is $D_{\mathrm{Ti}}=5.5 \times 10^{-14}$, that of $\alpha$-Fe is $D_{\mathrm{Fe} \alpha}=5 \times 10^{-15}$ and that of $\gamma$-Fe is $D_{\mathrm{Fe} \gamma}=3 \times$ $10^{-17} \mathrm{~m}^{2} \mathrm{~s}^{-1}$ at $\left.900^{\circ} \mathrm{C}\right) .{ }^{13)}$ Hence, imbalance in mass transfer across the interface promotes void generation in the diffusion zone. The existence of micro-voids have been observed in the temperatures of $700-850^{\circ} \mathrm{C}$ and $800^{\circ} \mathrm{C}$ by Hinotani et al. and Orhan et al. for the diffusion couples of $\mathrm{Ti} / \mathrm{Ni}$ and stainless steel/Ti-6Al-4V respectively. ${ }^{12,20)}$ In the present investigation, these voids are not found in SEMBSE perhaps owing to their sub-microscopic size. However, they may form even at $800^{\circ} \mathrm{C}$ and grow at $900^{\circ} \mathrm{C}$ bonding temperature. Therefore, at low processing temperature the effect of micro-voids is marginal and at higher joining temperature these voids may provide additional embrittlement to the diffusion-welded joints.

\section{Conclusions}

Solid-state diffusion bonding has been carried out between commercially pure titanium and 304 stainless steel to produce transition joints in the temperature range of 800 $900^{\circ} \mathrm{C}$ for $9 \mathrm{ks}$ under load in vacuum. The characterization of interface reveals:

The diffusion zone contains intermetallics like $\sigma, \lambda, \chi$, FeTi and $\mathrm{Fe}_{2} \mathrm{Ti}_{4} \mathrm{O}$ oxides. All these compounds are brittle and are responsible for lowering in bond strength.

The width of the intermetallic phases is minimum at $800^{\circ} \mathrm{C}$, maximum at $850^{\circ} \mathrm{C}$ and decreases at $900^{\circ} \mathrm{C}$ processing temperature.

Strain generation at the bonding interface has been observed for all the diffusion-welded joints and it reaches at the highest extent for $900^{\circ} \mathrm{C}$ joining temperature.

At $800^{\circ} \mathrm{C}$, bond strength becomes maximum due to thinner width of the intermetallics. Decrement in bond strength at $850^{\circ} \mathrm{C}$ processing temperature is due to enhancement in width of brittle intermetallic phases.

Sharp fall in the strength of the transition joints at $900^{\circ} \mathrm{C}$ is the cumulative effect of presence of brittle intermetallic compounds, maximum amount of strain generation and growth of micro-voids.

\section{REFERENCES}

1) G. Cam and M. Kocak: Int. Mater. Rev., 43 (1998), 1.

2) R. S. Bushby, K. P. Hicks and V. D. Scott: J. Mater. Sci., 31 (1996), 4545 .

3) F. A. Calvo, A. Urena, J. M. G. DeSalazar and F. Molleda: J. Mater. Sci., 24 (1989), 4152

4) J. Fielding: Proc. of Conf. on Advances in Welding Process, The Welding Institute, Abington Hall, Cambridge, (1970), 1.

5) M. Ghosh and S. Chatterjee: Mater. Charact., 48 (2002), 393.

6) J. L. Murray: Phase Diagrams of Binary Titanium Alloys, ASM International, Metals Park Ohio, (1990), 99.

7) V. Ganeshan, V. Seetharaman and V. S. Raghunathan: J. Nucl. Mater, 118 (1983), 313.

8) M. Ghosh and S. Chatterjee: Mater. Sci. Eng., A358 (2003), 152.

9) M. Eroglu, T. I. Khan and N. Orhan: Mater Sci. Technol., 18 (2002), 68.

10) M. Ghosh and S. Chatterjee, "Characterisation of reaction products and their effects on strength properties of transition joints formed between titanium and stainless steel," Scand. J. of Metall., accepted for publication.

11) P. Villars, A. Prince and H. Okamoto: Handbook of Ternary Phase Alloys, ASM International, Materials Park Ohio, (1995), 8903.

12) S. Hinotani and Y. Ohmori: Trans. Jpn Inst. Met., 29 (1988), 116.

13) B. Aleman, I. Gutierrez and J. J. Urcola: Mater. Sci. Technol., 9 (1993), 633.

14) M. Ghosh, K. Bhanumurthy, G. B. Kale, J. Krishnan and S. Chatterjee, "Diffusion bonding of titanium to 304 stainless steel," $J$. Nucl. Mater, accepted for publication.

15) R. S. Timsit: Acta Metall., 33 (1985), 97.

16) G. B. Kale, R. V. Patil and P. S. Gawde: J. Nucl. Mater., 257 (1998), 44.

17) G. B. Kale, K. Bhanumurthy and J. Krishnan: Proc. of Int. Welding Conf., Bhaba Atomic Research Centre, Mumbai, (1996), A-042-1.

18) H. Kato, M. Shibata and K. Yoshikawa: Mater. Sci. Technol., 2 (1986), 405.

19) M. Ghosh, K. Bhanumurthy, G. B. Kale and S. Chatterjee: "Effects of reaction products on the bond strength of the transition joint formed between titanium and stainless steel," Mater. Sci. Technol., accepted for publication.

20) N. Orhan, T. I. Khan and M. Eroglu: Scr. Metall., 45 (2001), 441. 